\title{
A ANGÚSTIA EM ANDREIEV E DOSTOIÉVSKI: DUAS EXPERIÊNCIAS OPOSTAS
}

THE ANGUISH IN ANDREIEV AND DOSTOIÉVSKI: TWO OPPOSITES EXPERIENCES

Rodrigo do Prado Bittencourt*

* rodrigopbittencourt@gmail.com

Possui graduação em Ciências Sociais (USP, 2007), mestrado em Teoria e História Literária (UNICAMP, 2013) e doutoramento em Literatura de Língua Portuguesa: Investigação e Ensino (Universidade de Coimbra, 2017). Segue a linha de estudos que contempla as relações entre Literatura e Sociedade. Publicou mais de 30 artigos acadêmicos; em seis países: Alemanha, Brasil, Chile, Estados Unidos, França e Portugal. É membro do corpo editorial de nove revistas acadêmicas, leciona há mais 10 anos e tem publicado contos

RESUMO: Este artigo analisa comparativamente duas obras da Literatura Russa. Trata-se do romance O Eterno Marido (Vechnyj mиzh - Beчный мyж), de 1870, de Fiódor Dostoiévski (1821-1881), e da novela Os Sete Enforcados (Рассказ о семи повешенных), de 1908, de Leonid Andreie (1871-1919). Estas duas obras trabalham o tema da angústia. São angústias opostas, porém. A angústia de Veltchaninov, personagem principal da obra de Dostoiévski, está ligada à fatuidade de um homem ocioso, bem-educado, sem família e longe dos a migos. Ele não tem vínculos sociais ou atividades a exercer, daí provém sua "hipocondria" Sua situação agrava-se com a chegada denac̃a à morte e ao nedo de que esta mote seja en vão. Texto axpermenta à movador e ousado, esta obra a malisa ontogicame Texto experida vida e de seu e ousado, esta obra analisa ontologicam. da vida e de seu fim. É uma angústia essencialmente humana, enquanto retratada por Dostoiévski em seu romance é verdadeiramente civilizacional e histórica, pois tem como uma de suas causas principais a influência da condição social de Veltchaninov sobre seu temperamento.

PALAVRAS-CHAVE: Dostoiévsk; Andreiev; Angústia; Morte; Civilização.

ABSTRACT: This article comparatively analyzes two works of Russian Literature. These are the novel The Eternal Husband (Vechnyj mиzh - Bеиный мyж), of 1870, by Fyodor Dostoevsky (1821-1881), and the novel The Seven Who Were Hanged (Рассказ о семи повеменных), of 1908, by Leonid Andreye (1871-1919). These two works deal with the theme of anguish. They are opposite anxieties, however. Veltchaninov's anguish, the main character of Dostoevsky's work, is linked to the fact that he is a well-mannered, idle man with no family and far from friends. He has no social ties or activities to pursue, hence his "hypochondria" Their situation is aggravated by the presents an existential anguish, linked to the death sentence and the fea that this death will be in vain. Experimental, innovative and audacious, this work analyzes ontologically the question of life and its end. It is an essentially human anguish, while the one portrayed by Dostoevsky in his novel is truly civilizational and historical, for it has as one of its main causes the influence of Veltchaninov's social condition on his temperament.

KEYWORDS: Dostoiévsk; Andreiev; Anguish; Death; Civilization 


\section{Introdução ${ }^{1}$}

O intuito deste artigo é confrontar comparativamente duas obras de autores russos, do final do século XIX e início do XX. Ele nasce da percepção de que, embora bem distintas entre si, as duas obras apresentam um elo em comum: a recorrente questão da angústia, na Literatura Russa. Com efeito, esse tema está presente em algumas das principais obras de alguns dos mais relevantes autores da geração que marcou a Rússia do século XIX e pré-revolucionária (referese aqui à revolução bolchevique, de outubro de 1917).

Para fazer apenas um breve levantamento, percebe-se que a angústia tem importante papel em Crime e Castigo, de Dostoiévski, acompanhando Raskolníkov de perto por toda a sua trajetória após tornar-se um assassino, só deixando-o quando encontra o a mor e a paz, em sua vida de condenado, na Sibéria. Os Irmãos Karamázov, também de Dostoiévski, apresenta a angústia de Dmitri Karamázov, ao se ver injusta mente acusado de ter assassinado seu próprio pai, um crime que desejara cometer. Mais que Dimitri, entretanto, é seu irmão Aliócha que se encontra mais entregue à angústia, pois pressente a inocência do acusado.

Anna Kariênina, de Tolstói, por sua vez, traz a angústia da mulher condenada socialmente por ter deixado seu primeiro casamento, para unir-se a outro marido. Trata-se de uma forte condenação moral por parte da sociedade russa de então e Anna sofre profundamente. Já Pais e Filhos, de Turguêniev, traz não apenas a angústia das gerações mais velhas, diante das inovações da juventude, percebendo-se então fraca e ultrapassada; mas também a angústia dessa própria juventude que - tentando desvencilhar-se das heranças do passado, para fundar uma nova ordem social - não sabe separar o joio do trigo e acaba por negar a tudo e a todos, ficando desprovida de certezas e esteios para sua nova fundação.

Quanto à Gógol, a angústia está fortemente presente em suas curtas novelas sobre a vida urbana de São Petersburgo Analisando, sobretudo, as vidas dos pequenos funcionários públicos, o escritor russo-ucraniano recorre ao fantástico para expressar a angústia vivida pelo baixo escalão do Estado Tzarista. Em O Capote, a angústia de Akáki Akákievitch, ao ter seu capote novo roubado, por exemplo, é tão grande que o leva a fazer o que nunca antes em sua vida fizera enfrentar os seus superiores hierá rquicos. Mais que isso, ela leva-o à morte e a tornar-se um fantasma a assombrar os ricos donos de luxuosos capotes, dos bairros mais elegantes de São Petersburgo.

Esta é uma obra fundamental para a Literatura Russa. Afinal, disse Dostoiévski, a respeito de si e de sua geração de escritores russos: "Todos nós descendemos d'O Capote" 
(DOSTOIÉVSKI apud BEZERRA, 1990, p. 25). Já em Diário de um Louco, novamente a questão da subordinação humilhante e extrema é encarada e chega a ser tão grave que causa a loucura de um funcionário de baixo escalão hierárquico. Assim, o recorrente tema da angústia aparece diversas vezes na Literatura Russa, ainda que de forma variada e diversa. Analisar-se-á, aqui, sua presença a partir do conhecimento das duas obras estudadas.

\section{O eterno marido - Dostoiévski}

Romance de Dostoiévski em que dois inimigos convivem de perto e os temas do adultério, da vingança, da paternidade, da mentira e, sobretudo, da dignidade são trabalhados. Com efeito, é uma obra em que dois inimigos estão o tempo todo se digladiando em busca, sobretudo, de sua própria dignidade, cujo obstáculo maior é a existência do outro.

Veltchaninov foi amante da esposa de Pavel Pavlovitch Trussotski (Natalia Vassilievna), quando residia na cidade de T... junto do casal, e o reencontro com esse, depois de nove a nos, faz com que ele se sinta culpado e vil. Pavel Pavlovitch agora sabe que o antigo a migo, a quem ele sempre admira ra fora um dos amantes de sua falecida esposa e isso ofende tremendamente seu orgulho e seu sentimento de dignidade. Inicia-se, aí, portanto, uma dura batalha entre dois inimigos que não deixam de ter sido íntimos um do outro; o que os faz muito mais perigosos e virulentos para com seu opositor.

Para complicar essa situação, Trussotski tra z consigo uma filha de sua esposa e de Veltchaninov; filha cuja existência esse último sequer suspeitava e que aquele apenas há pouco tempo descobrira não ser sua. Trussotski é mau para com a menina, querendo vingar-se de sua falecida esposa por meio dos sofrimentos causados à criança e isto confrange Veltchaninov. A menina, Lisa, sofre muito com a morte da mãe e com o comportamento cruel que aquele que ela acreditava ser seu pai passa a ter; torturada e negligenciada, ela adoece e, por mais que Veltchaninov ainda tentasse restabelecê-la, acaba por morrer. A crueldade, aliás, segundo Mikhailóvski é um tema recorrente na obra de Dostoiévski; crueldade sem motivo, sem finalidade, sem explicação. O simples deleite de fazer o outro sofrer. O Eterno Marido está repleto desse tipo de crueldade tão marcadamente dostoiévskiana, sobretudo por parte de Pavel Pavlovitch.

$\mathrm{O}$ rápido momento em que Lisa conviveu com Veltchaninov, entretanto, foi o suficiente para transforma $r$ a vida dele: hipocondríaco, inconstante, nervoso e ocioso, Veltchaninov não tinha uma razão de viver; sua filha passa a ser essa razão e ele torna-se forte, generoso e decidido. É verdade que sua morte o abalou muito e destruiu parte da estabilidade emocional que ele havia conquistado, mas 
fato é que ele nunca voltou à pusila nimidade do começo da narrativa.

O Eterno Marido é um romance em que Dostoiévski demonstra sua usual capacidade de análise psicológica, em uma narrativa forte e intensa, mas marcadamente fluida e mais leve que a de clássicos como Crime e Castigo ou Irmãos Karamazov. Éverdade que a narra tiva parece perder um pouco de sua verossimilhança no penúltimo capítulo, chamado "Análise", em que o protagonista a nalisa tudo que viveu nos últimos tempos, suas transformações e a figura de Pavel Pavlovitch Trussotski. Afinal, Veltchaninov demonstra-se muito consciente e clarividente nesse capítulo, destoando do resto da narrativa. Ainda assim, não se pode dizer que essa capacidade analítica seja completamente inaceitável uma vez que o momento em que ele luta por sua vida diante de seu inimigo torna-se uma epifania em que tudo que antes parecia obscuro e mal resolvido se ordena e ganha sentido, dentro de si. Nesse momento, ele resolve não apenas seus conflitos com Trussotski, mas ta mbém os conflitos internos que toda essa história lhe causava.

A descrição do comporta mento de Trussotski com relação à Lisa certamente é pungente e envolve o leitor, gerando compaixão e perplexidade. Está, sem dúvida, entre as páginas mais importantes da Literatura sobre o tema da vileza humana e da maldade perturbada de alguém que perdeu o controle sobre seus próprios sentimentos e vontades, deixando-se levar pelos mais sórdidos impulsos. A crueldade está em seu auge, em meio à narrativa. O que choca o leitor e dá força ao texto é o fato de que Pavel Pavlovitch não é inteiramente mau e, em realidade, nunca antes agira assim, tendo sempre se comportado de maneira cordata e humana. Assim, Dostoiévski demonstra que qualquer um pode chegar ao grau tão baixo que ele chegou, pois ele não era e nunca foi um demônio, mas apenas uma pessoa normal; alguém normal e cruel, de uma crueldade extremamente humana corriqueira. Mais uma vez, vê-se que o autor está a sondar os desdobramentos da crueldade em personagens que não passam de pessoas banais e comuns.

As idas e vindas, as incertezas e contradições de Pavel Pavlovitch e sua inconstância demonstram que ele ainda lutava contra o que havia de sórdido e incontrolável em si próprio. Como já se disse, tanto ele quanto Veltchaninov estão em busca de sua dignidade. Essa busca passa pela virtual destruição do outro, que constitui a fonte de perturbação da paz e do equilíbrio pessoal. Destruição desejada, mas temida: Pavel Pavlovitch quer e ao mesmo tempo não quer a vitória sobre seu rival, pois precisa dele para si próprio. Veltchaninov é odiado justamente por ter e ser tudo aquilo que Pavel Pavlovitch desejava para si. Odiar e torturar o outro é uma necessidade para Pavel Pavlovitch, como era 
para o homem do subsolo diante de Lisa, em Memórias do subsolo.

Páviel Pávlovitch, ao contrário do que faz parecer, precisa de Vieltchâninov para consumar quaisquer desejos, daí de não serà toa que o faça escolher o regalo que pla neja dar à pretensa noiva, daí de não ser à toa que o apresente à fa mília dela, faça com que todos os presentes gostem e clamem por ele. Da amizade, surge a rivalidade, a qual, sob a égide do ódio impotente, esconde uma profunda veneração de Páviel Pávlovitch por Vieltchâninov, veneração (BERCHEZ, 2019, 189).

Pavel Pavlovitch tenta transformar essa possibilidade de extermínio moral e psíquico em realidade empírica, pegando de uma navalha para assassinar seu inimigo. Refletindo sobre isso depois, Veltchaninov conclui que o ato não fora premeditado. Aliás, o mesmo Pavel Pavlovitch que muitas vezes não desejava senão provocar e ofender o antigo amante de sua esposa, outras vezes parecia submisso, cordato e mesmo amigo. Aliás, é justamente esta inconstância - que também afeta Veltchaninov, deve-se dizer - que acaba por ir protelando uma resolução final e definitiva e muito provavelmente é ela que leva às coisas a chegarem ao ponto que chegaram.

Em O eterno marido, a personagem Pavel só se sentia inserido socialmente com a presença de sua mulher, não de Natalia propriamente, mas da figura da esposa, razão por que gostava que outros homens a admirassem e abusassem do seu convívio. Após a morte de Natalia, Pavel procura se casar novamente para retornar à vida de eterno marido (RESENDE, 2011, 130).

Veltchaninov conclui que, se logo de início, tivesse se rebaixado ao nível de Pavel Pavlovitch e ridiculamente o abraçado e chorado junto dele, bebendo e relembrando o passado que a ambos dizia respeito, provavelmente nada de grave teria acontecido. Nem Veltchaninov, nem Pavel Pavlovitch, entretanto, conseguiam admitir a si mesmos que se tratava de descer a este nível e expor-se ao ridículo, revelando ao outro os seus segredos de forma melodramática e grotesca, como esses dramalhões da vida real que acontecia m cotidia na mente nas tabernas, dentre os mujiques embriagados.

Contudo se eu tivesse chorado, é possível que ele realmente me perdoasse, pois tinha uma vontade imensa de me perdoar! [...] Por isto mesmo, vinha bêbado, a fim de dizê-lo, ainda que por entre esgares; não poderia fazê-lo em estado normal... E ele bem que gostava de fazer palhaçadas, oh, se gostava! Como ficou contente quando me obrigou a beijá-lo! Apenas não sabia então como acabaria o caso: um abraço ou uma punhalada? [...] O mais monstruoso dos monstros é 
monstro com sentimentos nobres (DOSTOIÉVSKI, 2003, 186-187).

Dostoiévski, portanto, reconhece nessas atitudes exageradas um efeito de catarse que Pavel Pavlovitch, sem o saber, buscava. E buscava por quê? Porque ele como um marido traído submisso e conformado - o que Veltcha ninov chama de "eterno marido" - não desejava matar o homem que sempre admirara e imitara. Em Pavel Pavlovitch havia um ódio misturado com a mor; com inveja; com imitação.. No fundo, ele reconhecia Veltchaninov como um superior e um modelo a ser seguido e, assim, seu coração ficava dividido entre prestar-lhe homenagem e matá-lo. Ao menos, essa é a imagem que o próprio Veltchaninov faz de Pavel Pavlovitch e que, no interior da economia da obra, mostra-se muito verossímil. Veltchaninov reflete acerca dessa mistura de a mor e ódio que há em seu rival:

"Sim! É a verdade absoluta! - decidia-se ele, aprofundando cada vez mais em seus pensamentos e procedendo a uma análise. - Esse Quasímodo de T... era suficientemente estúpido e grato para se encher de amores pelo amante da própria mulher, em que não notara nada durante vinte anos! Respeitou-me nove anos seguidos, lembrava-se de mim com veneração e conservou na memória minhas 'lucubrações'. E eu não sabia de nada, meu Deus! Ele não podia estar mentindo ontem! Mas a mava-me acaso ontem, quando expressou seu a mor e disse: 'Ajustemos as contas?' Sim, a mava-me por ódio e este amor é o mais forte... (DOSTOIÉVSKI, 2003, 185).

Ainda assim, mesmo diante desse enredo repleto de ódio, dissimulação, fraqueza, admiração e toda uma série de sentimentos aparentemente contraditórios, a narrativa da obra apresenta a pusilanimidade inicial de Veltchaninov de modo detalhado e ricamente construído. Esse assunto é essencial para o desenrolar da história, pois apresenta o caráter social que motiva a condição da personagem, imputando-lhe fraquezas que serão superadas a partir do descobrimento do fato de que ele é pai e, finalmente, da vitória sobre seu rival/a migo/inimigo: Pavel Pavlovitch.

Com efeito, essa obra não deixa de trazer em seu bojo toda a refinada análise psicológica típica de Dostoiévski, mas o faz sem se afastar de um tema eminentemente social e muito debatido na segunda metade do século XIX e início do século XX: os condicionamentos coletivos que influenciariam o agir individual. Assim, $O$ eterno marido é um romance de caráter profundamente "psicológico", mas ta mbém de cunho muito cla ra mente "sociológico", partindo da observação de que o estado de apatia de Veltchaninov, no início da narrativa, devia-se a um fenômeno socia a mplamente difundido dentre as pessoas de sua classe, idade 
e gênero. Seria, portanto, um mal "civilizacional" (temporal e histórico), mas que acabaria por dar lugar a um tema "universal" (a angústia humana).

Essa perspectiva algo sociológica não é exclusiva desse livro de Dostoiévski. Com efeito, em Crimee Castigo, o estado de pavor, remorso, angústia e doença de Raskolníkov, logo após o assassinato por ele cometido, configura muito bem um caso de anomia, segundo a formulação desse conceito por Émile Durkheim (2019). Como em Crime e Castigo, porém, a narrativa de Dostoiévski, no texto aqui estudado, vai muito além da análise das condições sociais de suas personagens, invadindo até mesmo os campos da religião, do misticismo e da Metafísica. O que não diminui a importância dessa dimensão "sociológica" no desenrolar da narrativa e na caracterização das personagens e do contexto que as envolve.

Talvez o que haja de mais interessante em $O$ Eterno Marido seja justa mente o fato de que esse caráter social permeie a obra do início ao fim, sendo necessário para a estruturação da narrativa e, ao mesmo tempo, uma tese defendida pelo livro. Afinal, a condição social não apenas situa a vida de Veltchaninov no presente, até o aparecimento de Pavel Pavlovitch e Lisa, mas condiciona a visão que cada um tem de si e dos outros. Pavel Pavlovitch pertenceria, na sua própria visão, a um tipo de esposos que, submissos, sempre adorariam suas esposas e admirariam aqueles que conseguissem ganhar a atenção e o afeto delas. Com efeito, o próprio título apresenta a definição desse tipo humano, dessa espécie de configuração social-psicológica, que explicaria o comportamento de Pavel Pavlovitch. Por isso, a angústia que perpassa a obra é, ainda que íntima, de caráter profunda mente social e histórica. Pavel Pavlovitch não é o único. Ele não passa de um exemplar de um grande grupo de pessoas que não conseguem viver por si próprias, mas precisam se apoiar em outras para que passem a fazer sentido para si mesmas e para o mundo. Em Pavlovitch, destaca-se a "crueldade do talento de Dostoiévski", para usar uma expressão de Mikhailóvski (2013).

\section{Os sete enforcados - Andreiev}

Essa obra é quase que um convite ao novo, ao inesperado e ao impensável; por isso soa um pouco artificial, mas de uma artificialidade saborosa. Afinal, é essa mesma artificialidade que agrada: tem-se a sensação de que foi criado um novo mundo pelo autor e que somos uns dos poucos que têm acesso a ele, que esta mos mesmo a descobrir segredos da vida que os demais mortais nem sonham haver. Mikhailova a nalisa as técnicas literárias usadas por Andreiev para criar essa expressão do inexprimível: 
1. No original: "The semantics of inexpressible is described as the functionalsemantic category. The description of the analytical and synthetic multi-level transmission means of semantics of inexpressible is given: one-word, as part of indivisible combinations and in the word combinations that represent descriptive parts. Four significant results of studying the existence of elements of inexpressible in the analyzed novel

have been defined. It was

revealed that Andreev's five

of seven characters were

marked with the markers of

inexpressible. The following

text function means of

transmitting semantics

of inexpressible were

identified and characterized:

characterological,

actualization of content-

conceptual information,

actualization of means of

expression, in particular, the

antithesis; it was shown that

this lexeme also actualizes

the content-conceptual

information ancep

antithesis of life and death in

an art space story, is also a

symbol of cross-cuting story.
A semântica do inexprimível é descrita como a categoria semântico-funcional. A descrição dos meios analítico e sintéticos de transmissão multinível da semântica do inexprimível é dada: com uma só palavra, como parte de combinações indivisíveis e nas combinações de palavras que representam partes descritivas. Quatro resultados significativos do estudo da existência de elementos de inexprimível no romance analisado foram definidos. Foi revelado que cinco dos sete personagens de Andreiev foram marcados com os marcadores de inexprimível. Foram identificados e caracterizados os seguintes meios de função textual de transmissão da semântica do inexprimível caracterológico, atualização da informação conteúdoconceitual, atualização dos meios de expressão, em particular, a antítese; foi mostrado que esse lexema também atualiza a informação conteúdo-conceitual e a antítese de vida morte em uma história do espaço da arte, sendo também um símbolo de história transversal. A interação da semântica do inexprimível com o lexema que indica o mundo da alteridade - o desconhecido - também foi revelada (MIKHAILOVA, 2016, p. 573 , trad. edição). ${ }^{1}$

O livro é assustador. Como não poderia ser, se o tema é a morte e a mais cruel e sem sentido das mortes? Mortes dos que lutam por justiça e dos pobres injustiçados que nunca foram respeitados enquanto seres humanos. Violento e profundo, ele deixa o leitor perplexo com o maior desafio do ser humano: seu fim. Com efeito, o questionamento de qual é o sentido da vida - se é que é possível encontrar algum sentido - perpassa toda a obra, mas sem suscitar respostas de qualquer tipo; sem indícios sequer de que as dores desse questionamento possam ser aplacadas.

Andreiev é duro. Não ameniza nada. Não é possível deixar de perceber a dor diante do vazio e a perplexidade do nada intrínseco e inelutável. Justamente por isso o livro vale a pena. Aqui a morte não é enaltecida de modo romântico; tampouco é justificada por alguma ideologia que coloque alguma causa como mais importante que a própria vida. Não! A morte simplesmente aparece em toda sua força corriqueira, cruel e inflexível. Aparece e fica. Cabe a nós conseguir responder a ela; se é que isso é possível. A morte é; o homem apenas surge e logo passa. A perenidade ontológica está nela, que afeta a todos os seres vivos e ainda pode servir de metáfora para os inanimados. O homem é apenas um acidente histórico.

Obra essencial. Afinal, como desde a Ilíada nos é apresentado, é a postura diante da morte que dá valor ou não ao que se vive. No clássico homérico, é mesmo ela a personagem central e não Aquiles. Segundo uma tradição mitológica, o Pelida a prefere, desde que gloriosa, à vida longa e próspera ofertada por Tétis, sua mãe. Em Andreiev,
The interaction of semantics of inexpressible with the lexeme indicating the world of otherness - the unknown - was also revealed"

(MIKHAILOVA, 2016, p. 573). 
não há glória: há medo, dor, paranoia, opressão, burocracia e vazio.

Os heróis que morrem pela liberdade, por um ideal, aqu são mostrados enquanto seres que não podem escapar às debilidades diante do ocaso. Pior, por mais nobres que pareçam, também serão mortos e esquecidos. O que há de mais cruel nisso tudo é justamente isto: a segunda morte, a morte cultural. Foi desse esquecimento que fugiu Odisseu ao deixar Calipso. Afinal, não bastando a morte natural, Andreiev concede também essa outra. Nos clássicos homéricos, a morte física é preferível ao esquecimento; aqui, não há como escapar de nenhum dos dois males. É como se Homero tivesse sido vencido e todos os valores sobre os qua is repousa a fundação da cultura ocidental não passassem de balela e estupidez, sonhos infantis diante dos fatos.

Depois de destruir todos os recursos que alguém pode ter para enfrentar os dilemas da vida - isso a que chamamos cultura - só resta mesmo o vazio. Andreiev não hesita em apresentar a seus leitores esse vazio e, diferentemente de Dostoiévski e Tolstoi, que buscavam no Cristianismo e na Cultura Russa o respaldo para que suas personagens pudessem enfrentar os duros percalços e dilemas da vida, Andreiev não traz consigo nada. Não há crença ou convicção que se mostre forte o suficiente para enfrentar a dura verdade da morte inelutável. Não há como dela escapar e ninguém se encontra verdadeiramente preparado para enfrentá-la.

\section{Considerações finais}

Percebe-se, pela a nálise realizada, a diferença funda menta no tratamento do tema da angústia pelos dois textos. Foi escolhido esse livro de Dostoiévski ao invés dos mais famosos, que trazem vivências da angústia de cunho mais existencial, para ressaltar o fato de que esse autor também soube tratar de ambientes mundanos, da futilidade e fatuidade. Esse livro talvez seja, de todos os que o grande escritor escreveu, um dos mais próximos da Literatura Francesa. Afinal, Balzac, Stendhal, Fla ubert e outros grandes nomes da literatura desse país souberam analisar fria mente o a mbiente mundano, frio, fátuo e empolado da burguesia e da aristocracia francesas do século XIX. Dostoiévski não costumava se debruçar sobre temas assim, mas tinha como cerne o deslindar dos conflitos psicológicos-existenciais de suas personagens. Em O Eterno Marido, entretanto, surge um cenário social mais detalhado, como pano de fundo para essa a nálise existencial.

Nada melhor para fazer o contraponto a essa obra de Dostoiévski que o livro de Andreiev, com personagens densos e perfil experimental, árduo, filosófico e existencial. 
13. Para as informações da presente seção, o material básico de consulta consistiu: nas gramáticas de Smyth (1984) e de Ragon (2007) bem como nos livros Helleniká (BRANDÃO; SARAIVA; LAGE, 2009) e La lingua geniale (MARCOLONGO, 2016).
O que não impede O Eterno Marido de ser um profundo estudo da psique humana. O estudo é magnífico e a personagem aparentemente superficial, fútil e tola (bem diferente de Raskolníkov, Aliócha, ou o prisioneiro de Recordações da Casa dos Mortos) revela uma profundidade recôndita de certo modo inesperada. Essa sua fatuidade, num contraste com Pavel, nos coloca diante das diversas características e possibilidades do ser humano. Em Dostoiévski, todavia, as categorias jamais são estanques: o Veltchaninov que se apresentava superficial se mostra uma pessoa conturbada por uma intensa luta interior, em torno de suas memórias, afetos e busca pelo sentido da vida. Enquanto Pavel Pavlovitch, que a princípio se mostrava forte e decidido, é quem vai descortinar a fraqueza recôndita de seu orgulho ferido, de sua incapacidade de sepultar seu passado e a dor que o dilacera e o impede de ter controle sobre si próprio e sua vida.

Durante todo o romance, e o seu final confirma esta impressão, percebe-se que Veltchaninov, devido à sua fraqueza moral, encontra-se ma is suscetívela aborrecimentos e confusões que os demais homens. A própria personagem pensa assim. Com isso, sua perturbação e angústia podem ser relativizadas pelo leitor, que percebe que outro homem agiria de modo mais resoluto e resolveria com maior facilidade toda a questão. É a fraqueza de Veltchaninov que permite que o pusilânime Pavel Pavlovitch consiga irritá-lo tanto e, em alguns momentos, dominar sua vontade. Tratase, portanto, de toda uma situação que só pode existir graças a essa condição de fatuidade, ócio, insegurança e falta de projetos, que marca Veltchaninov e o angustia.

Veltchaninov vive uma angústia que se molda em meio aos fatos de uma vida comum, urbana e civilizada; dentro de seus padrões sociais. Bem diferente daquela vivida pelos condenados de Andreiev, que não são mais que simples avatares de uma situação que aflige a toda a humanidade desde seus primórdios até hoje: a morte. O enredo traçado por Andreiev poderia ocorrer com quaisquer condenados, de qualquer época ou povo. Já o romance de Dostoiévski emoldura-se nas condições de vida de uma classe rica e ociosa, que já não é religiosa e tampouco carrega consigo alguma outra crença, doutrina ou ideologia que a ampare. Uma classe que está transformando a Rússia, fazendo ela se tornar cada vez mais capitalista, colocando o dinheiro no lugar dos valores antigos. Algo que se dá de forma rápida e intensa, transformando sensibilidades e modos de enxergar o mundo, dando origem a novas configurações e maneira de se viver a angústia humana. 


\section{REFERENCIAS}

ANDREIEV, Leonid. Os Sete Enforcados. Coleção "Novelas Imortais". 2. ed. São Paulo: Rocco, 2015.

BAKHTIN, Mikhail. Problemas da poética de Dostoievski. Tradução de Paulo Bezerra. Rio de Janeiro: Forense Universitária, 2015

BERCHEZ, Amanda N. “O mais monstruoso dos monstros é o monstro com sentimentos nobres": 0 eterno marido, de Dostoiévski, e a tradição romanesca. Revista Inventário, n. 23, Salvador, jul. 2019, p. 177-196.

BEZERRA, Paulo. Nascimento e Evolução de um Escritor. In: GÓGOL, Nikolai. 0 Capote e outras novelas de Gógol. Tradução de Paulo Bezerra. 1. Ed. Rio de Janeiro: Civilização Brasileira, 1990, pp. 11-26.

DOSTOIÉVSKI, Fiódor. Crime e Castigo. Tradução de Paulo Bezerra. 19. Ed. São Paulo: Editora 34, 2015

DOSTOIÉVSKI, Fiódor. 0 Eterno Marido. Tradução de Boris Schnaiderman. São Paulo: Editora 34, 2003.

DOSTOIÉVSKI, Fiódor. Os Irmãos Karamázov. Tradução de Paulo Bezerra. 2 volumes. 1. Ed. São Paulo: Editora 34, 2008.

DOSTOIÉVSKI, Fiódor. Memórias do subsolo. Tradução de Boris Schnaiderman. São Paulo: Editora 34, 2009.
DOSTOIÉVSKI, Fiódor. Recordações da Casa dos Mortos. Tradução de Nicolau S. Peticov. 3. Ed. São Paulo: Nova Alexandria, 2006.

DURKHEIM, Émile. 0 suicídio. São Paulo: WMF Martins Fontes, 2019

GÓGOL, Nikolai. 0 Capote. In: GÓGOL, Nikolai. 0 Capote e outras novelas de Gógol. Tradução de Paulo Bezerra. 1. Ed. Rio de Janeiro: Civilização Brasileira, 1990a.

GÓGOL, Nikolai. Diário de um Louco. In: GÓGOL, Nikolai. 0 Capote e outras novelas de Gógol. Tradução de Paulo Bezerra. 1. Ed. Rio de Janeiro: Civilização Brasileira, 1990b, pp. 59-85

GUIMARÃES, Ruth. Os caminhos de Dostoiévski. In: DOSTOIÉVSKI, Fiódor. 0 eterno marido. Tradução de Marina Guaspari; introdução de Ruth Guimarães. 2. ed. Rio de Janeiro: Nova Fronteira, 2017 p. 7-18.

HOMERO. Ilíada. Tradução de Frederico Lourenço. 1. Ed. São Paulo: Penguim/Companhia das Letras, 2013.

HOMERO. Odisseia. Tradução de Frederico Lourenço. Biblioteca Editores Independentes. 1. Ed. Lisboa: Cotovia, 2008.

MIKHAILOVA, M. Yu (2016). Semantics of inexpressible in 'The seven who were hanged' by L. Andreev. Liberal Arts in Russia, 5 (6), p. 573-579. 
MIKHAILÓVSKI, N. "Um talento cruel", trad. Sonia Branco. In: GOMIDE, Bruno (org.) Antologia do pensamento crítico russo (1802-1901). São Paulo: Editora 34, 2013, p. 425-508.

RESENDE, Kellen M. C. Intertexto ou hipertexto: as relações entre "Bolor" e "0 eterno marido". Revista Desassossego, 3(5), 2011 ,

p. 125-136. Disponível em: https://doi.org/10.11606/issn.21753180.v3i5p125-136. Acesso em: 15 dez. 2019.

TOLSTOI, Liev. Anna Kariênina. 2. Ed. São Paulo: Cosac Naify, 2005.

TURGUÊNIEV, Ivan. Pais e Filhos. 1. Ed. São Paulo: Cosac Naify, 2015

Recebido em: 01-01-2020 Aceito em: 18-05-2020. 